\title{
Jejunal immunoglobulin and antigliadin antibody secretion in adult coeliac disease
}

\author{
J F Colombel, F Mascart-Lemone, J Nemeth, J P Vaerman, C Dive, J C Rambaud
}

\begin{abstract}
We compared the local intestinal immunoglobulin (Ig) secretion in six adult patients with coeliac disease and nine control subjects by perfusion of a small bowel segment under an occluding balloon and analysis of the perfusion fluid for the content of $\mathrm{Ig}$ and secretory component. The results were compared to the number of Ig-containing plasma cells in the test segment. There was, respectively, a twofold and a fivefold increase in jejunal secretion rates of IgA (both monomeric and polymeric) and IgM in patients with coeliac disease compared with control subjects. The high IgA and IgM secretion rates parallel the increase of Igcontaining plasma cells in the lamina propria. In contrast, the IgG plasma cell density increase was barely significant in patients with coeliac disease and did not result in a high IgG secretion rate. The jejunal secretion rate of secretory component was significantly increased in patients with coeliac disease and no free dimeric IgA was present in the jejunal fluid. Antigliadin-IgA was detected in the serum and jejunal fluid of the six patients with coeliac disease. Antigliadin-IgA, however, was almost entirely polymeric IgA linked to secretory component in jejunal fluid, whereas $61 \%$ was dimeric IgA not linked to secretory component in serum. This result, combined with a raised secretory component secretion rate with no evidence of secretory component saturation, suggests that serum and intestinal antigliadin IgA might be of different origins in coeliac disease.
\end{abstract}

The immunological mechanisms in the pathogenesis of coeliac disease are still poorly understood. Although systemic cellular immune responses have been well studied, investigations of local mucosal immune responses have been limited and mainly based on in vitro studies. ${ }^{1}$ Enhanced intestinal secretion of immunoglobulins (Ig) has been shown in coeliac disease using organ culture systems $\mathrm{s}^{2-4}$ and, more recently, isolated small intestinal lymphocytes. ${ }^{5}$ Attempts, however, to measure in vivo Ig secretion in coeliac disease, by measuring concentrations of Ig in jejunal fluid, have shown various results with IgA secretion being described as higher, ${ }^{67}$ similar to ${ }^{8}$ or lower 9 than that in control subjects. Thus we studied the local intestinal Ig secretion in adult coeliac disease by perfusion of a small bowel segment under an occluding balloon and by analysis of the perfusion fluid for the content of immunoglobulins. ${ }^{10}$ The results were compared to Ig plasma concentrations and to the number of Ig-containing plasma cells in the test segment.
Increased serum antibody concentrations to gliadin have been well documented in patients with coeliac disease. ${ }^{11}$ Particularly, the demonstration of gliadin specific antibodies of the $\operatorname{IgA}$ isotype has been emphasised as being of great screening value. ${ }^{12-14}$ The origin of these antibodies, however, remains speculative. It has been shown that in children with acute coeliac disease, $57 \%$ of antigliadin IgA in serum is polymeric IgA (pIgA). ${ }^{15}$ The possibility has been suggested that in coeliac disease the mucosal production pIgA could exceed the possibilities of epithelial transport, resulting in a spillover of non-excreted pIgA antibodies from the intestinal mucosa into the circulation. ${ }^{15}$ Our experiments on in vivo Ig and secretory component jejunal secretion in patients with coeliac disease gave us the opportunity to study in parallel antigliadin $\operatorname{Ig} \mathrm{A}$ antibodies and their size in serum and jejunal fluid.

\section{Methods}

\section{PATIENTS}

Six patients with coeliac disease (two men and four women, mean age 50 years, range 16-77 years) gave informed consent to the study which was approved by the local ethics committee. All patients had active disease - that is, symptoms and subtotal villus atrophy of the jejunal mucosa. All patients had a symptomatic and histological response to gluten restriction, four after the perfusion and two before; the latter were studied because of their relapse due to failure to comply with the diet.

\section{JEJUNAL PERFUSION}

Segmental perfusion of the jejunum was performed according to Rambaud et al ${ }^{16}$ using a four lumen tube with a proximal occluding balloon. The tube was swallowed by the subject before dinner and the perfusion started after overnight fasting; the infusion point being located near the duodenojejunal junction under the inflated balloon (checked fluoroscopically) The gut was perfused with a $115 \mathrm{mmol} \mathrm{NaCl}$, $10 \mathrm{mmol} \mathrm{KCl}$, and $35 \mathrm{mmol}$ mannitol solution containing $1 \mathrm{~g} / \mathrm{l}$ of polyethylene glycol 4000 (PEG), at a rate of $10 \mathrm{ml} / \mathrm{minute}$. Four consecutive samples (each $20 \mathrm{~min}$ ) were collected after a 60 minute equilibration period. Perfusate samples were recovered at $0^{\circ} \mathrm{C}$. Diisopropylfluorosphosphate $(1 \mathrm{mM})$, a potent protease inhibitor, was added to an aliquot of each sample which was stored at $-20^{\circ} \mathrm{C}$ until aśsayed. During perfusion duodenal contents proximal to the 
balloon were continuously collected and discarded. Contamination of the jejunal samples by duodenal fluid bypassing the balloon was controlled by using two semiquantitative methods: detection of bromosulphophthalein, which was infused above the balloon into the duodenum, and detection of chymotrypsin and lipase activity in the perfusate. Any contaminated sample was discarded after detection. Absence of blood contamination was confirmed in all samples (Hemotest, Ames, France).

Immunoassays of proteins in serum and jejunal fluid were performed as previously described. ${ }^{10}$ Sedimentation profiles of $\operatorname{IgA}$ and secretory component in serum and jejunal fluid were analysed by sucrose density gradient ultracentrifugation as described earlier. ${ }^{10}$

The fluid flow rate at the sampling point (FRs) was calculated as follows: $F R s=F R p \times(P E G p) /$ (PEGs) where FRp is the fluid flow rate at the perfusion point, and (PEGp) and (PEGs) are the polyethylene glycol concentrations at the perfusion and sampling points, respectively. The secretion rate of each protein (PSR) was calculated according to the formula: $P S R=F R s \times$ (protein s), where (protein s) is the concentration of the protein at the sampling point and was expressed as $\mathrm{mg} \cdot \mathrm{min}^{-1} .40 \mathrm{~cm}^{-1}$ The results were compared with those of 11 control subjects previously studied under the same conditions, ${ }^{10}$ as well as with those of 11 new healthy volunteers. These new control values were not significantly different from.the former ones, ${ }^{17}$ confirming the reliability of our method.

\section{IMMUNOHISTOCHEMISTRY}

Endoscopic jejunal biopsy specimens were obtained through a colonoscope, just below the angle of Treitz, in all patients. Biopsy specimens were processed for immunohistochemistry as previously described. ${ }^{10}$ The fluorescence micrographs were analysed by morphometry using a semiautomatic image analyser (Nachet, NS 1000, Levallois-Perret, France). The numbers of plasmacytes $/ \mathrm{mm}^{2}$ of lamina propria were compared to those of nine control subjects studied under the same conditions. ${ }^{10}$ with coeliac disease (CD). Figures above horizontal bars indicate significant differences ( $p$ value) between $C$ and $C D$.
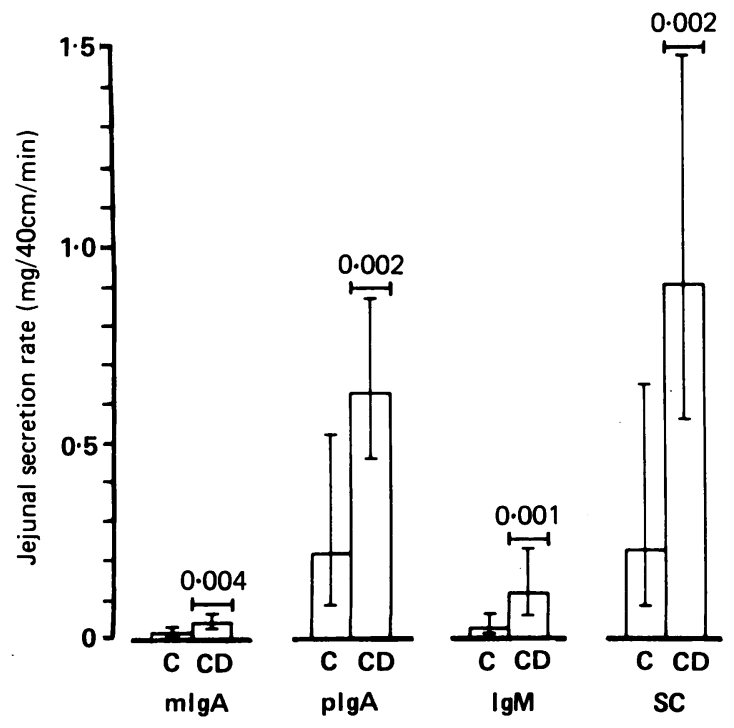

C CD

Protein concentrations in serum (g/l) of control subjects and patients with active coeliac disease. Results are expressed as geometric means (SEM)

\begin{tabular}{llll}
\hline & $\begin{array}{l}\text { Control subjects } \\
(n=11)\end{array}$ & $\begin{array}{l}\text { Patients with coeliac } \\
\text { disease }(n=6)\end{array}$ & Significance \\
\hline Albumin & $41.35(40.6$ to $42 \cdot 1)$ & $33.55(31.5$ to 35.7$)$ & $\mathrm{p}=0.002$ \\
IgG & $13.1(12.1$ to 14.1$)$ & $10.5(9.11$ to 12$)$ & $\mathrm{NS}$ \\
mIgA & $2.24(2$ to 2.5$)$ & $2.5(2.15$ to 2.9$)$ & $\mathrm{NS}$ \\
pIgA & $0.3(0.25$ to 0.36$)$ & $0.45(0.36$ to 0.57$)$ & $\mathrm{NS}$ \\
IgM & $0.95(0.87$ to 1.06$)$ & $0.61(0.49$ to 0.75$)$ & $\mathrm{p}=0.027$ \\
\hline
\end{tabular}

\section{ANTIGLIADIN ANTIBODIES}

Antigliadin IgA antibodies were detected in serum and jejunal samples by a solid phase radioimmunoassay as previously described. ${ }^{15}$ Antibody titres were expressed (a) in arbitrary units (AU), by reference to a standard binding curve established by serial dilutions of a strongly positive serum; (b) in AU per $\mu \mathrm{g}$ of total $\mathrm{IgA}$ in serum and in jejunal fluid. Serum and jejunal perfusates, obtained by the same technique, from 18 control patients hospitalised for other enteropathies (five with Crohn's disease, three with ulcerative colitis, and three with giardiasis) or for cirrhosis (seven) were also analysed as several workers have reported the presence of antigliadin antibodies in the serum of such patients. ${ }^{12-14}$

The molecular size distribution of the serum and jejunal antigliadin $\operatorname{IgA}$ of patients with coeliac disease was analysed by sucrose density gradient ultracentrifugation and proportions of pIgA and monomeric IgA (mIgA) antigliadin were measured by planimetry. ${ }^{10}$

\section{STATISTICS}

Results are expressed as geometric means (SE) of the geometric mean (SEM) and were compared by the Mann-Whitney U test.

\section{Results}

PROTEIN CONCENTRATIONS IN SERUM (Table) In patients with coeliac disease the albumin and IgM concentrations were significantly lower and the pIgA concentrations higher than in control subjects, although this last difference was not significant.

PROTEIN JEJUNAL SECRETION RATES (Fig 1) In patients with coeliac disease mIgA, pIgA, IgM, and secretory component secretion rates were significantly higher than in control subjects. There was no detectable secretion of pIgA unlinked to secretory component as shown by sucrose density gradient ultracentrifugation. Secretory component in perfusate samples of coeliac disease sedimented mainly with $\mathrm{pIgA}$, but $14 \cdot 4 \%$ (range $7-27$ ) was excreted as free secretory component compared to $6.9 \%$ (range $4-17)$ in controls $(p=0.05)$. The albumin and IgG secretion rates were similar in patients and control subjects.

IMMUNOHISTOCHEMICAL STUDIES (Fig 2)

The numbers per $\mathrm{mm}^{2}$ of cells containing IgA, 
Figure 2: Plasmacyte numbers per $\mathrm{mm}^{2}$ of lamina propria (geometric mean (SEM)) in 11 control subjects $(C)$ and six patients with coeliac disease $(C D)$. Figures above horizontal bars indicate significant differences ( $p$ value) between $C$ and $C D$.
Figure 3: Antigliadin IgA in serum and jejunal fluid from 18 control patients $(C)$ and six patients with coeliac disease $(C D)$. Columns represent medians.
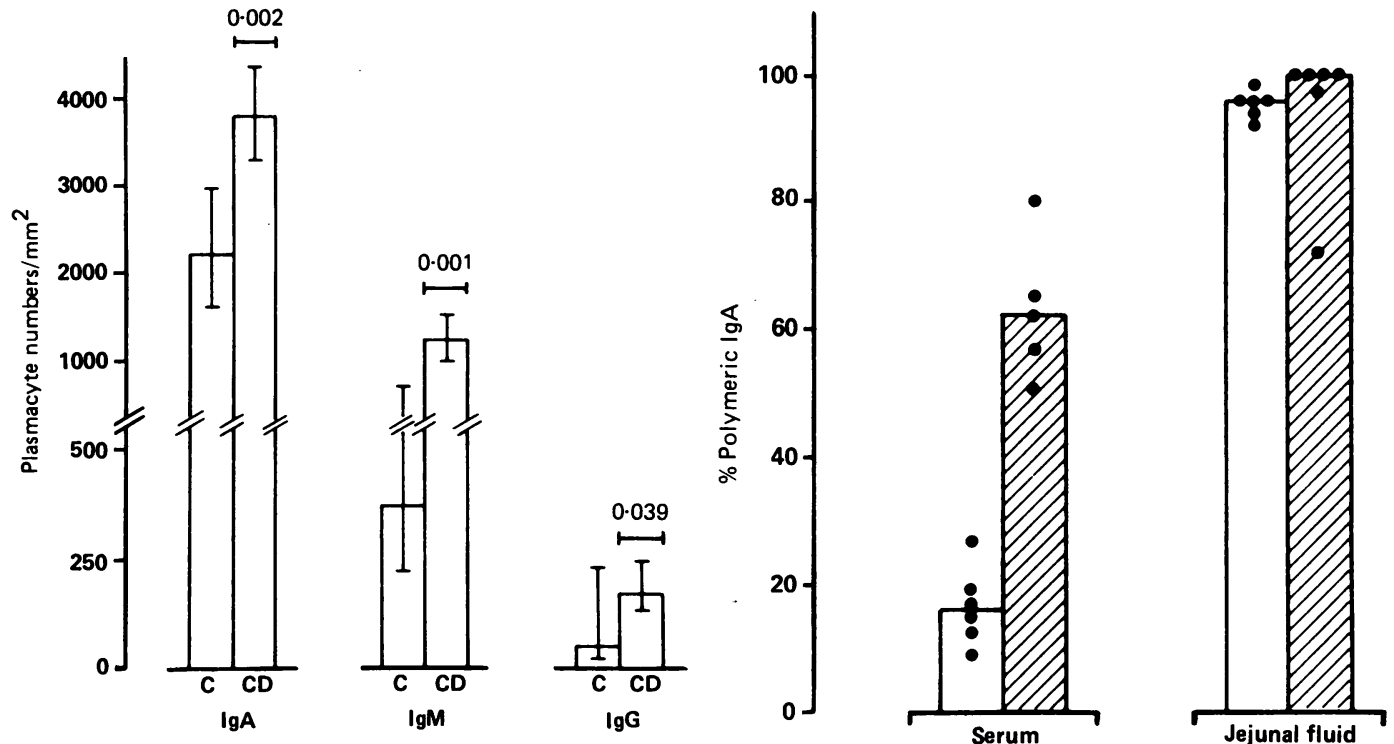

$\operatorname{IgM}$, and IgG in the jejunal lamina propria were significantly higher in coeliac patients than in control subjects.

Figure 4: Median percentages of polymeric IgA among total IgA (open columns) and among antigliadin IgA antibodies (hatched columns) in serum and jejunal fluid. Note that in serum there is a high percentage of antigliadin PIgA antibodies $\mathrm{v}$ a normal low percentage of total polymeric I $A$, in contrast to jejunal fluid where both parameters are about equally high.

\section{ANTIGLIADIN IGA}

In serum, antigliadin IgA antibodies were detected in all patients with coeliac disease and six of the 18 control patients (five cirrhosis and one Crohn's disease) (Fig 3). Antigliadin IgA titres were higher in patients with coeliac disease than in the six positive control patients, especially when expressed in AU/ $\mu$ g serum IgA as IgA concentrations were high in patients with cirr-

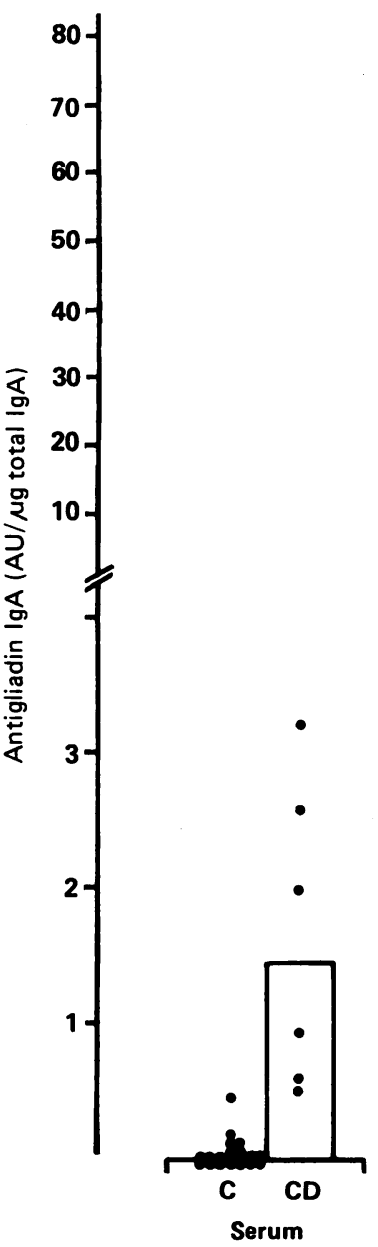

hosis. Antigliadin IgA was $61 \%$ (range 50-79) pIgA compared to $14.5 \%$ (range 9-26) of total IgA in serum (Fig 4). Antigliadin pIgA was mainly $10 \cdot 2 \mathrm{~S}$ dimeric IgA not linked to secretory component as shown by the absence of fixation of ${ }^{125}$ I-labelled antisecretory component antibodies to the antigliadin antibodies (Fig 5).

In jejunal fluid, antigliadin IgA antibodies were detected in all patients with coeliac disease and in three of the 18 control patients (one cirrhosis, one Crohn's disease and one ulcerative colitis) who were different from those with positive antigliadin IgA in serum (Fig 3 ). In coeliac disease antigliadin IgA activity was higher in jejunal fluid than in serum (Fig 3). It was almost $100 \%$ pIgA linked to secretory component (secretory IgA) compared to $94 \%$ (range 91-97) for total secretory IgA (Figs 4 and 5).

\section{Discussion}

In this study we have shown a twofold and a fivefold increase of jejunal secretion of $\operatorname{IgA}$ (both $\mathrm{mIgA}$ and $\mathrm{pIgA}$ ) and $\operatorname{IgM}$, respectively, in patients with untreated coeliac disease compared with control subjects. So far, attempts to quantify jejunal Ig secretion in vivo in coeliac disease have given conflicting results. In these studies samples were contaminated by saliva, gastric juice, and pancreatic proteolytic enzymes and the Ig concentrations were affected by water movements across the intestine. Our results reinforce in vitro studies showing enhanced local secretion of $\operatorname{IgA}$ and $\operatorname{IgM}$ using in vitro organ cultures or isolated intestinal lymphocytes. ${ }^{2-5}$ The high IgA and IgM secretion rates observed in coeliac disease in our study parallel the increase of Ig synthesising plasma cells in the lamina propria. Similar alterations in plasma cell isotype frequency, with the density of IgM plasma cells being increased relative to IgA cells, have been reported in other studies. ${ }^{17-19}$ In contrast with IgA and IgM, the increase in IgG 


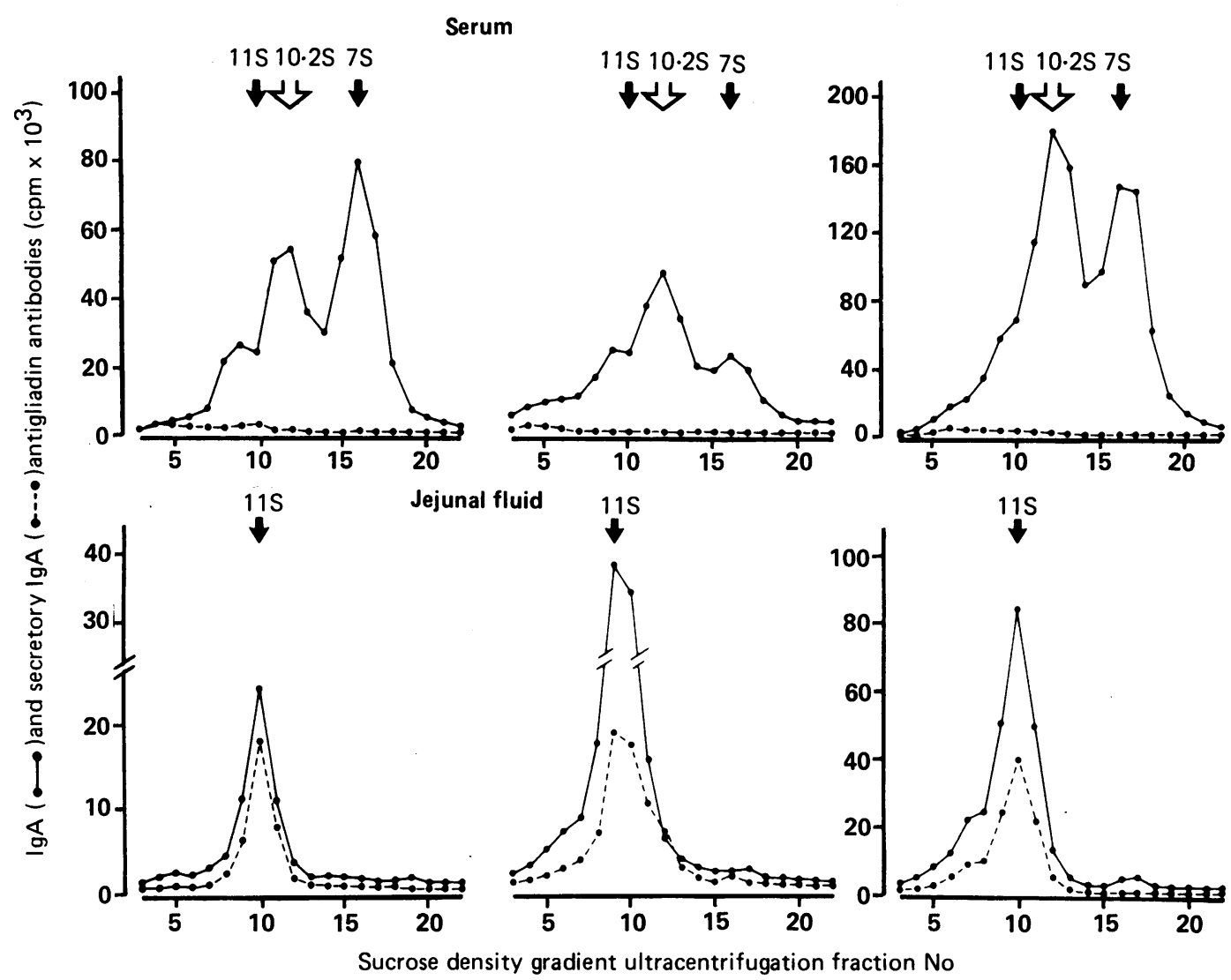

Figure 5: Molecular size profiles of antigliadin IgA in serum and jejunal fluid samples from three different patients with coeliac disease as assessed by sucrose density gradient ultracentrifugation. Arrows indicate sedimentation positions of marker $7 S$ monomeric serum IgA, 10-2S dimeric serum IgA, and milk $11 S$ secretory IgA. Sedimentation from right to left.

plasma cell density was barely significant in coeliac disease and did not result in a high jejunal IgG secretion rate. In addition, IgG in the jejunal lumen mainly comes from plasma by passive seepage $^{10}$ and the serum concentration of $\operatorname{IgG}$ was normal in patients with coeliac disease.

Our study provides further information on the adjustment of secretory component transport capacity to secretory Ig production in the jejunum. In coeliac disease, contrary to a previous report, ${ }^{20}$ but in accordance with previous immunohistochemical observations, ${ }^{2122}$ the hyperplastic crypt epithelium seems to function normally with regard to external transport of IgA and IgM since the jejunal secretion rate of secretory component was strikingly high and no free dimeric IgA was present in the jejunal fluid. In coeliac disease secretory component is present not only in the crypt epithelium but also in the surface epithelium where its concentration increases with increasing villus atrophy. ${ }^{23}$ Thus, in contrast with a recently reported case of massive plasma cell infiltration of the digestive tract, ${ }^{24}$ secretory component is not a rate-limiting factor of Ig secretion in jejunal lumen in coeliac disease: both secretory component synthesis by lengthened crypts and pIgA and IgM production by increased numbers of infiltrating plasma cells are high and seem to cooperate to cause a significant increase in pIgA and IgM output. Furthermore, secretory component production in coeliac disease could exceed Ig production as suggested by a significant increase in free secretory component in the jejunal fluid. Along the same line an accumulation of free secretory component at the mucosal surface has been shown by immuno- histochemical studies in coeliac disease. ${ }^{23}$ The mechanism of increased synthesis of secretory component in coeliac disease is unknown. It has been shown recently that interferon- $\gamma$ upregulates the intracellular pool and epithelial membrane expression of functional secretory component in a dose-dependent manner. ${ }^{25}$ Increased lymphokine production - that is, interferon- $\gamma$ - by intraepithelial T lymphocytes, which accumulate in coeliac disease mucosa, might promote secretory component synthesis and thus the external transport of pIgA and IgM. ${ }^{26}$

As the origin of serum antigliadin $\operatorname{IgA}$ in coeliac disease remains uncertain, we compared its molecular form in serum and jejunal fluid. Our results showing a different size in serum and in jejunal secretion, combined with a raised secretory component secretion rate, indicate that the presence of antigliadin $\operatorname{IgA}$ in serum might not be the result of the reabsorption of intestinal antibodies through a damaged mucosa nor the consequence of an inadequate secretory component synthesis. Our data suggest that serum and intestinal antigliadin $\operatorname{IgA}$ might be of a different origin. Intraluminal antibodies are synthesised in the gut mucosa. Serum antigliadin IgA could be synthesised by transient circulating blood B cells since those cells, which secrete $40 \%$ of total $\operatorname{IgA}$ as pIgA when cultivated in vitro, ${ }^{27}$ have been recently shown to secrete antigliadin antibodies in some cases of active coeliac disease. ${ }^{28}$ Alternatively, serum antigliadin pIgA might be of mucosal origin, whereas antigliadin mIgA could be synthesised by memory cells, after migration to the spleen, lymph nodes, and 
bone marrow which are synthesising $\mathrm{mIgA} .{ }^{27} \mathrm{It}$ is also conceivable that secretory component would be a rate-limiting factor for the secretion of antigliadin pIgA antibodies in the ileum or colon, or both, because at those sites, but not in the jejunum, the specific $B$ cell population would also be expanded, but without concomitant upregulation of epithelial secretory component expression, resulting in antigliadin pIgA antibodies spillover in the circulation.

We thank J P Dehennin, C Franchisseur, J Van den Broeck, and J De Mets for excellent technical help.

1 Strober W. Gluten sensitive enteropathy, an abnormal immunologic response of the gastrointestinal tract to dietary protein. In: Shorter RG, Kirsner JB, eds. Gastrointestinal immunity for the clinician. Orlando: Grune and Stratton, $1985 \cdot 75-112$

2 Wood GM, Howdle PD, Trejdosiewicz LK, Losowsky MS. Jejunal plasma cells and in vitro immunoglobulin produc tion in adult coeliac disease. Clin Exp Immunol 1987; 69 123-32.

3 Fluge G, Asknes L. Quantification of immunoglobulins after organ culture of human duodenal mucosa. 7 Pediatr Gastro enterol Nutr 1983; 2: 62-70.

4 Ciclitira PJ, Ellis HJ, Wood GM, Howdle PD, Losowsky MS. Secretion of gliadin antibody by coeliac jejunal mucosa biopsies cultured in vitro. Clin Exp Immunol 1986; 64: biopsies

5 Crabtree JE, Heatley RW, Losowsky ML. Immunoglobulin secretion by isolated intestinal lymphocytes: spontaneous production and T-cell regulation in normal small intestin and in patients with coeliac disease. Gut 1989; 30: 347-54.

6 Lancaster-Smith M, Kumar P, Marks R, Clark ML, Dawson AM. Jejunal mucosal immunoglobulin-containing cells and jejunal fluid immunoglobulins in adult coeliac disease and dermatitis herpetiformis. Gut 1974; 15: 371-6.

7 Labrooy JT, Hohmann AW, Davidson GP, Hetzel PAS, Johnson RB, Shearman DJC. Intestinal and serum antibody in coeliac disease: a comparison using ELISA. Clin Exp Immunol 1986; 66: 661-8.

8 Douglas AP, Crabbe PA, Hobbs JR. Immunochemical studies of the serum, intestinal secretions and intestinal mucosa in patients with adult celiac disease and other forms of the
celiac syndrome. Gastroenterology 1970;59:414-25.

9 Girard JP, de Kalbermatten A. Dosage et propriétés anticorps des immunoglobulines des sécrétions duodénales de la maladie coeliaque. Ann Immunol (Inst Pasteur) 1973; 124C 555-65.

10 Jonard PP, Rambaud JC, Dive C, Vaerman JP, Galian A, Delacroix DL. Secretion of immunoglobulins and plasma
proteins from the jejunal mucosa. $\mathcal{f}$ Clin Invest 1984; 74: 525-35.

11 Kieffer M, Frazier PJ, Daniels NWR, Coombs RRA. Wheat gliadin fractions and other cereal antigens reactive with antibodies in the sera of coeliac patients. Clin Exp Immunol 1982; 50: 651-60.

12 Unsworth DJ, Kieffer $M$, Holborow EJ, Coombs RRA, Walker-Smith JA. IgA anti-gliadin antibodies in coeliac disease. Clin Exp Immunol 1981; 46: 286-93.

13 Savilahti E Perkkio M, Kalimo K, Viander M, Vainio E, Reunalo T. IgA anti-gliadin antibodies: a marker of mucosal damage in childhood coeliac disease. Lancet 1983 ; i: $320-2$.

14 Koninckx CR, Giliams JP, Polanco I, Pena AS. IgA antigliadin Koninckx CR, Giliams JP, Polanco I, Pena AS. IgA antigliadin
antibodies in celiac and inflammatory bowel disease. antibodies in celiac and inflammatory bou

15 Mascart-Lemone F, Cadranel S, Van den Broeck J, Dive C, Vaerman JP, Duchateau J. IgA immune response patterns to gliadin in serum. Int Arch Allergy Appl Immunol 1988; 86: 412-9.

16 Rambaud JC, Duprey F, Nouel O, Hostein J, Delpech B, Bernier JJ. Assessment of the accuracy of segmental perfusion under an occluding balloon for measuring the intrajejunal secretion of albumin and immunoglobulin. Gut 1981; 22: 371-5.

17 Marteau P, Colombel JF, Nemeth J, Vaerman JP, Dive C Rambaud JC. Immunological study of the histologically non involved jejunum during Crohn's disease: evidence for reduced in vivo secretion of secretory IgA. Clin Exp Immunol 1990; 80:196-201.

18 Dhesi I, Marsh MN, Kelly C, Crowe P. Morphometric analysis of small intestinal mucosa. 2. Determination of lamina propria volumes; plasma cell and neutrophil populations within control and coeliac disease mucosae. Virchorws Arch (Pathol Anat) 1984; 403: 173-80.

19 Scott BB, Goodall A, Stephenson P, Jenkins D. Small intestinal plasma cells in coeliac disease. Gut $1984 ; 25: 41-6$.

20 Shiner RJ, Ballard J. Mucosal secretory IgA and secretory piece in adult coeliac disease. Gut 1973; 14: 778-83.

21 Baklien $\mathrm{K}$, Brandtzaeg P, Fausa $\mathrm{O}$. Immunoglobulins in jejunal mucosa and serum from patients with adult coeliac jejunal mucosa and serum from patients with adu

22 Scott H, Brandtzaeg P, Thorsby E, Baklien K, Fausa O, Ek J. Mucosal and systemic immune response patterns in celiac disease. Ann Allergy 1983; 51: 233-9.

23 Scott H, Brandtzaeg P, Solheim BJ, Thorsby E. Relation between HLA-DR-like antigens and secretory component (SC) in jejunal epithelium of patients with coeliac disease or dermatitis herpetiformis. Clin Exp Immunol 1981; 44: 233-8.

24 Colombel JF, Rambaud JC, Vaerman JP, et al. Massive plasma cell infiltration of the digestive tract. Secretory component as the rate-limiting factor of immunoglobulin secretion in external fluids. Gastroenterology 1988; 95: 1106-13.

25 Sollid LM, Kvale D, Brandtzaeg P, Markussen G, Thorsby E. Interferon- $\gamma$ enhances expression of secretory component, Interferon- $\gamma$ enhances expression of secretory component,
the epithelial receptor for polymeric immunoglobulins. the epithelial receptor for

26 Brandtzaeg P, Sollid LM, Thrane PS, et al. Lymphoepithelial interactions in the mucosal immune system. Gut 1988; 29 , 1116-30

27 Kutteh WH, Prince SJ, Mestecky J. Tissue origins of huma polymeric and monomeric IgA. 7 Immunol 1982; 128: 990-5.

28 Lycke N, Kilander A, Nilsson LA, Tarkowski A, Werner N. Production of antibodies to gliadin in intestinal mucosa of patients with coeliac disease: a study at the single cell level. Gut 1989; 30: 72-7. 